\title{
SATELLITE ALTIMETRY AND KEY OBSERVATIONS: WHAT WE'VE LEARNED, AND WHAT'S POSSIBLE WITH NEW TECHNOLOGIES
}

\author{
Robert B. Scott ${ }^{(1)}$, Mark Bourassa ${ }^{(2)}$, Dudley Chelton ${ }^{(3)}$, Paolo Cipollini( ${ }^{(4)}$, Raffaele Ferrari ${ }^{(5)}$, Lee-Lueng Fu ${ }^{(6)}$, \\ Boris Galperin $^{(7)}$, Sarah Gille ${ }^{(8)}$, Huei-Ping Huang ${ }^{(9)}$, Patrice Klein ${ }^{(10)}$, Nikolai Maximenko ${ }^{(11)}$, Rosemary \\ Morrow $^{(12)}$, Bo Qiu ${ }^{(13)}$, Ernesto Rodriguez ${ }^{(6)}$, Detlef Stammer ${ }^{(14)}$, Remi Tailleux $^{(15)}$, Carl Wunsch ${ }^{(5)}$ \\ ${ }^{(1)}$ The University of Texas at Austin, 10100 Burnet Rd. Austin, TX 78758 USA, and the National Oceanography Centre, \\ Southampton, Waterfront Campus, European Way, Southampton SO14 3ZH, UK, Email: r.b.scott@soton.ac.uk \\ (2) COAPS (Center for Ocean-Atmospheric Prediction Studies), Florida State University, 236 R. M. Johnson Bldg. \\ 32306-2840 Tallahassee USA, Email: bourassa@coaps.fsu.edu \\ ${ }^{(3)}$ COAS (College of Oceanic and Atmospheric Sciences), Oregon State University, 104 Oceanography Admin. Bldg., \\ Corvallis, OR 97331-5503 USA, Email: chelton@coas.oregonstate.edu \\ ${ }^{(4)}$ National Oceanography Centre, Southampton, Waterfront Campus, European Way, Southampton SO14 3ZH, \\ United Kingdom, Email: cipo@noc.soton.ac.uk \\ ${ }^{(5)}$ Dept. of Earth, Atmospheric, and Planetary Sciences, Massachusetts Institute of Technology, 77 Massachusetts Ave. \\ Cambridge, MA 02139,USA, Email: rferrari@mit.edu; cwunsch@mit.edu \\ (6) Jet Propulsion Laboratory, M/S 300-323, 4800 Oak Grove Drive, Pasadena, CA 91109 USA, \\ Email: Ilf@pacific.jpl.nasa.gov; ernesto.rodriguez@jpl.nasa.gov \\ (7) University of South Florida, College of Marine Science, 140 7th Avenue South, St. Petersburg, FL 33701, USA, \\ Email: bgalperin@marine.usf.edu \\ ${ }^{(8)}$ Scripps Institution of Oceanography, University of California San Diego, 9500 Gilman Drive, San Diego, La Jolla, \\ CA 92093-0225, USA, Email: sgille@ucsd.edu \\ (9) Department of Mechanical and Aerospace Engineering, Arizona State University, PO Box 2260, Tempe, \\ AZ 85280-2260 USA, Email: hp.huang@asu.edu \\ (10) LPO, IFREMER (Laboratoire de Physique des Océans/French Institute for exploitation of the Sea/Institut Français \\ de Recherche pour l'Exploitation de la Mer), BP 70, 29280 Plouzané, France, Email: patrice.Klein@ifremer.fr \\ ${ }^{(11)}$ IPRC/SOEST (International Pacific Research Center/School of Ocean and Earth Science and Technology), \\ University of Hawaii, 1680 East West Road, POST Bldg. \#401, Honolulu, HI 96822, USA, \\ Email: maximenk@hawaii.edu \\ ${ }^{(12)}$ LEGOS/OMP (Laboratoire d'Études en Géophysique et Océanographie Spatiales/L'Observatoire Midi Pyrénées), \\ 14 Avenue Edouard Belin, 31400 Toulouse, France, Email: rosemary.morrow@cnes.fr \\ (13) SOEST (School of Ocean and Earth Science and Technology,) University of Hawaii at Manoa, 1000 Pope Road, \\ Honolulu, HI 96822, USA, Email: bo@soest.hawaii.edu \\ (14) Universität Hamburg, Zentrum für Marine und Atmosphärische Wissenschaften, Institut für Meereskunde, \\ Bundesstr. 53; 1. Stock; Raum 140, D-20146 Hamburg, Germany, Email: stammer@ifm.uni-hamburg.de \\ ${ }^{(15)}$ Department of Meteorology, University of Reading, Earley Gate, PO Box 243, Reading, RG6 6BB, UK, \\ Email:r.g.j.tailleux@reading.ac.uk
}

\section{INTRODUCTION}

The advent of high accuracy satellite altimetry in the 1990's brought the first global view of ocean dynamics, which together with a global network of supporting observations brought a revolution in understanding of how the ocean works [1]. At present a constellation of flying satellite missions routinely provides sea level anomaly, sea winds, sea surface temperature (SST), ocean colour, etc. with mesoscale resolution $(50 \mathrm{~km}$ to $100 \mathrm{~km}, 20$ to 150 days) on a near global scale. Concurrently, in situ monitoring is carried out by surface drifters, Argo floats, moorings, sea gliders as well as ship-borne CTD (ConductivityTemperature-Depth) and XBT (Expendable Bathythermograph) (to measure profiles of temperature and salinity), and ADCP (Acoustic Doppler Current Profiler) (to measure current velocity profiles).
This global observational system allowed observational oceanography to develop into an essentially quantitative science. This became possible because 1) the accuracy and volume of observations exceeded critical values, 2) numerous studies demonstrated good agreement between independent datasets, and critically 3 ) the data resolution crossed the threshold of revealing much of the mesoscale in two-dimensions, when previously it was only revealed in one-dimension along satellite ground tracks [2] with wide gaps in between. Fortuitously computing power kept pace allowing basin scale numerical ocean models to cross the threshold of revealing the mesoscale around the turn of the century [3]. The mesoscale is characterized by the most energetic motions and strong nonlinear interactions, issuing in a more complex range of phenomena. Below in Sect. 1 we present some highlights of this development. In Sect. 2, we describe 
future prospects, and Sect. 3 provides a reminder of the importance of maintaining continuity of high-quality observations. We conclude in Sect. 4 with discussion of integrating optimizing the observing system.

The benefits to society from development of quantitative dynamical oceanography, as with most scientific disciplines, while indirect, are no less real. Ocean dynamics forms an important foundation for climate dynamics and biological oceanography, developments of which have direct impacts on agriculture and fishing. A critical development in the last decade has been global ocean forecasting, which was non-existent before the Global Ocean Data Assimilation Experiment (GODAE). Assimilation of satellite altimeter data, SST data, and in situ Argo data are all critical elements, without which GODAE could not be possible.

This white paper comes at a critical juncture in ocean observing. While the utility of the observing network is firmly grounded in the success of the past, and technological advances promise the possibility of substantial gains, we still lack the commitment for sustained funding of even the existing observing network. We wish to express herein our sincere concern for the future of ocean observing, and in particular the satellite altimeter and supporting observations (especially scatterometer and drifter data).

\section{PROGRESS IN OCEANOGRAPHY FROM SATELLITE ALTIMETRY AND SUPPORTING OBSERVATIONS}

\subsection{Global View of Linear Rossby Waves}

i) Theoretical understanding of complexity of linear Rossby waves

Linear standard normal-mode theory (LST hereafter) was, prior to satellite altimetry, the main framework for oceanic Rossby waves. Some important features of the standard Rossby wave modes are: 1) that they are all stable and energetically decoupled; 2) that they have a period that increases with latitude up to several years at high-latitude, 3) that they are nearly nondispersive at low wavenumbers (i.e. equal group and phase speeds at long wavelengths), 4) that they are strongly dispersive at high wavenumbers, with the zonal phase speed approaching zero as the wavenumbers increase.

Nearly all these characteristics appear to be inconsistent to various degrees with those of westward propagating signals (WPS) observed in satellite altimeter data collected over the past 17 years. Given the gross simplifications of the LST, it is perhaps not surprising that LST does not fit the observations well. But interestingly [4] (CS96 hereafter) found observed phase speeds, as measured by the Radon Transform (RT hereafter), to be systematically faster by a factor of up to two to three than the longwave phase speed predicted by the LST for the first baroclinic mode at mid- and high-latitudes. Furthermore, [5] suggest that actual westward propagation is nearly nondispersive throughout the whole wavenumber range. These results prompted much theoretical work over the past decade. The main results are that the background zonal mean flow [6] and rough topography [7] are each, on their own, able to bring theoretical phase speeds closer to CS96's RT phase speed estimates in the long wave limit, although room for improvement exists. The best agreement is achieved by combining the effects of a background mean flow and variable bottom topography [8], [9], [10] and [11] but theoretical issues remain open. With regard to dispersion, the background mean flow can potentially make Rossby waves nondispersive at high-wavenumbers [12]. Reference [13] suggests that combined barotropic-baroclinic mode Rossby waves might explain the non-dispersive variability observed in the North Pacific. Reference [14] find secondary peaks in the RT, which they interpreted as evidence of higher-baroclinic modes, though another possibility would be nonlinear eddies, see Sect. 1.2 below.

\section{ii) Climatic importance of linear Rossby waves}

The ocean impacts human society through marine resources and Earth's climate. The tropical Pacific phenomenon of El Nino-Southern Oscillation (ENSO) provides a well-known example whose coupled atmosphere-ocean nature and global impacts have been appreciated since the 1980s. Below we describe another important example, the Pacific Decadal Oscillation (PDO), one of the largest climate signals in the North Hemisphere [15]. Here too observationally driven ocean science was essential for developing our understanding of the coupled climate system.

It is now well established that the large-scale, windinduced sea surface height ( $\mathrm{SSH})$ variability is controlled by baroclinic Rossby wave dynamics (e.g. [16], [17], [18], [19], [20] and [21]). Specifically, the large-scale SSH changes can be hindcast by integrating the anomalous wind-stress curl forcing along the Rossby wave characteristics along a latitude line from the eastern boundary.

Figure 1a shows the altimeter-derived SSH anomaly signals averaged in the latitudinal band of $32-34^{\circ} \mathrm{N}$ in the North Pacific Ocean as a function of time and longitude. Notice that the decadal SSH changes in the eastern North Pacific can be qualitatively explained by the wind stress curl variability associated with the PDO, with centre of action around $160^{\circ} \mathrm{W}$. Specifically, when the PDO index is positive (see Fig. 1c), the Aleutian Low intensifies and shifts southward, and this works to generate negative SSH anomalies near $160^{\circ} \mathrm{W}$ in the eastern North Pacific 
through surface wind stress driven Ekman divergence. The opposite is true when the PDO index is negative: wind-induced Ekman convergence in this case results in regional, positive SSH anomalies near $160^{\circ} \mathrm{W}$. SSH anomalies generated in the eastern North Pacific tend to propagate westward at the speed of baroclinic Rossby waves of $\sim 3.8 \mathrm{~cm} / \mathrm{s}$, taking many years to cross the basin to reach the Kuroshio Extension east of Japan.

Figure 1b shows the time-longitude plot of the SSH anomaly field in the same $32-34^{\circ} \mathrm{N}$ band modeled by the linear Rossby wave model with the use of the monthly wind stress curl data from the National Centers for Environmental Prediction-National Center for Atmospheric Research (NCEP-NCAR) reanalysis [22]. As expected, the Rossby wave model captures well all of the large-scale SSH anomaly signals that change sign on decadal timescales. The linear correlation coefficient between the observed and modeled SSH anomaly fields is $r=0.45$ and this coefficient increases to 0.53 when only the interannual SSH signals are retained in Fig. 1a. This quantitative comparison confirms the notion that the decadal Kuroshio Extension modulations detected by the satellite altimeter data over the past 15 years are initiated by the incoming $\mathrm{SSH}$ anomaly signals generated by the PDO-related wind forcing in the eastern North Pacific.

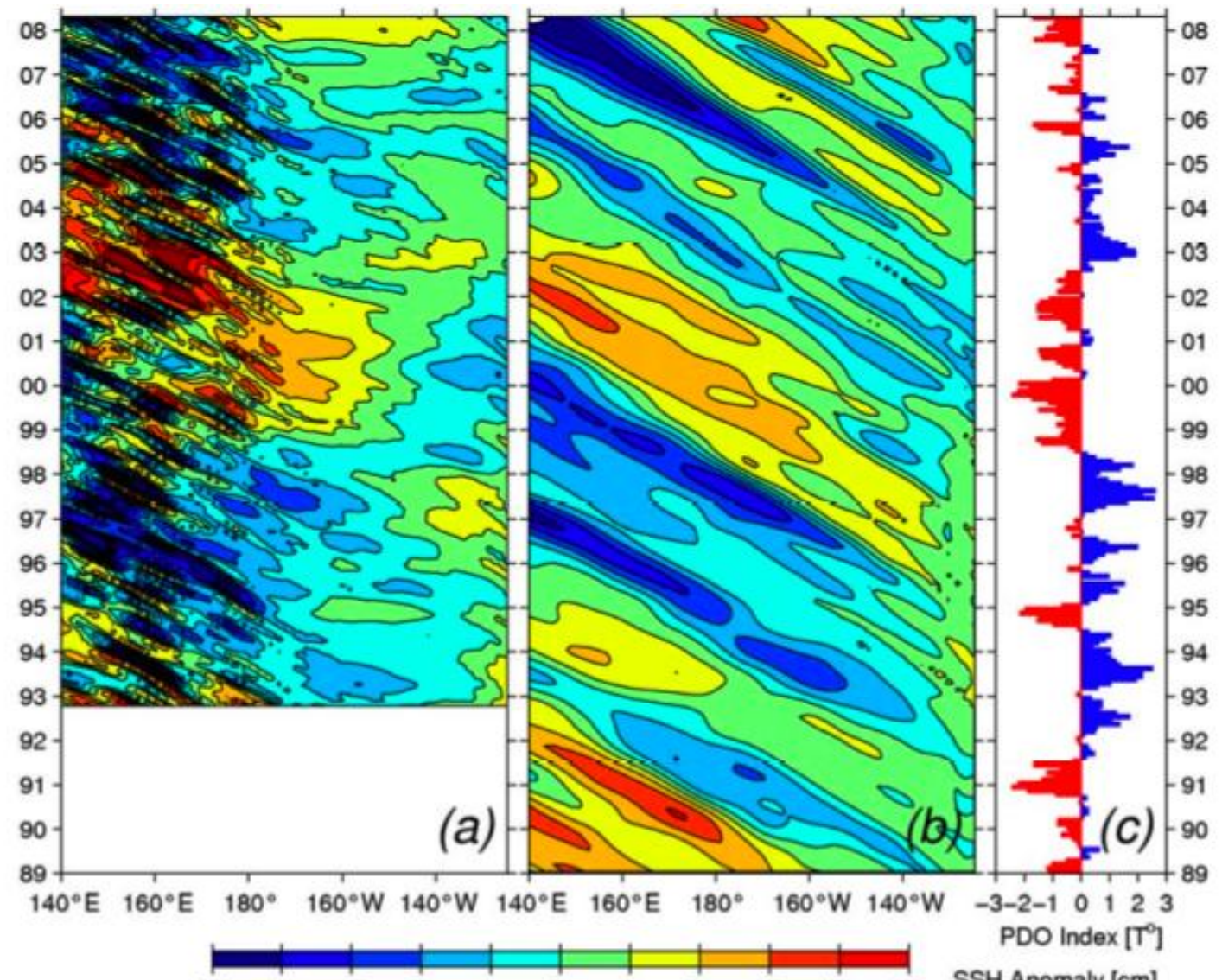

Figure 1: (a) SSH anomalies along the zonal band of $32-34^{\circ} \mathrm{N}$ from the satellite altimeter data. (b) Same as panel a) but from the wind-forced baroclinic Rossby wave model. (c) PDO index from http://jisao.washington.edu/pdo/PDO.latest. Figure from [20].

\subsection{The Nonlinear Threshold}

While the revolution in the 1990s came from the first global monitoring of the ocean, the revolution of the present decade has come from crossing the more subtle but equally important barrier of increased spatial/temporal resolution. The larger scale motions in the ocean are mostly linear phenomena, albeit with nonlinearity arising from coupling with atmospheric phenomena, e.g. ENSO and the PDO. In contrast the mesoscale motions (dozens to a few hundreds of kilometers) are governed by nonlinear dynamics, characterized by strong self-interaction of oceanic eddies. Nonlinearity generically brings more complexity [23]. Theoretical dynamical models since 
the 1970s predict a rich phenomenology ([24], [25], [26], [27], [28], [29] and [30] and many others) yet with only local and scant observational support. Only in the last few years has it been possible to observe the nonlinear phenomena and quantify their interactions.

Traditional altimeters in exact-repeat missions measure sea-surface height ( $\mathrm{SSH}$ ) along intersecting ground tracks. The regions between tracks form diamond patterns within which SSH is never sampled. Multiple altimeters operating simultaneously significantly improve the sampling. The degree to which this improves the resolution of SSH fields depends on the energy level of unresolved mesoscale variability, how well coordinated the orbit parameters are (repeat period, orbit inclination and measurement accuracy), the amount of spatial and temporal smoothing applied to the observations, and the subjectively chosen tolerance for residual errors [31]. The residual errors for a given amount of smoothing can vary geographically and temporally in complicated ways, especially for small amounts of smoothing.

For a single satellite like Jason-2, constructed SSH fields have a resolution of about $6^{\circ}$ in wavelength. The resolution is approximately doubled to about $3^{\circ}$ for SSH fields constructed from observations from two altimeters (Jason-2 and ENVISAT (Environmental Satellite)), or even tripled to about $2^{\circ}$ resolution with well-coordinated missions like Jason-2 and Jason-1 [31]. For Gaussian eddies, these wavelength resolutions of $6^{\circ}, 3^{\circ}$ and $2^{\circ}$ correspond to e-folding eddy scales of $80 \mathrm{~km}, 60 \mathrm{~km}$ and $40 \mathrm{~km}$, respectively. The above results apply to the smoothing procedure applied by AVISO (Archiving, Validation and Interpretation of Satellites Oceanographic data) [32] to construct SSH fields from Jason-2 and ENVISAT and their predecessor combinations of one altimeter in a 10-day repeat orbit (TOPEX (Ocean TOPography Experiment)/Poseidon followed by Jason-1) and another altimeter in a 35-day repeat orbit (ERS-1 followed by ERS-2 (European Remote Sensing satellite)). The variability is attenuated for wavelengths shorter than about $3^{\circ}$, see also [33].

\section{i) Propagating features}

The doubling of the spatial resolution of sea-surface height (SSH) fields constructed by AVISO [32] from the merged measurements by two simultaneously operating altimeters (one in a 10-day repeat orbit and the other in a 35-day repeat orbit) has dramatically altered the earlier interpretation of westward propagating variability based on TOPEX/Poseidon data only. It is now evident that most of the extratropical variability at wavelengths of $\mathrm{O}(100-500 \mathrm{Km})$ that was thought to be linear baroclinic Rossby waves modified by the mean flow and bathymetry is actually westward propagating nonlinear eddies that are nearly ubiquitous in the World Ocean (upper panel of Fig. 2). The variability due to Rossby waves remains significant at wavelengths of $\mathrm{O}(1000 \mathrm{Km})$ and longer.

An automated eddy tracking procedure identifies nearly 30,000 features with lifetimes of 16 weeks and longer. These observed features propagate nearly due west with small poleward and equatorward deflections of cyclonic and anticyclonic features, respectively, at approximately the speed of nondispersive baroclinic Rossby waves [34]. These propagation characteristics are consistent with theories for large, nonlinear eddies [26]. Additionally, zonal wavenumber-frequency spectra reveal little evidence of dispersion, again consistent with nondispersive eddy propagation although [12] find nondispersion at high wavenumber due to mean flow effects).

The most telltale evidence that most of the observed features are nonlinear eddies is the predominance of large nonlinearity parameter $U / c$, where $U$ is the maximum particle velocity within each feature and $\mathrm{c}$ is its translation speed. Features with U/c >1 contained trapped fluid. The average nonlinearity parameter exceeds 1 everywhere outside of the tropical band $20^{\circ} \mathrm{S}$ to $20^{\circ} \mathrm{N}$ (middle panel of Fig. 2). Moreover, U/c $>1$ for more than $98 \%$ of the extratropical eddies for both cyclones and anticyclones (bottom panels of Fig. 2). Even within the tropical band, more than $88 \%$ of the features are nonlinear. These results are broadly consistent with the findings of [35]. 

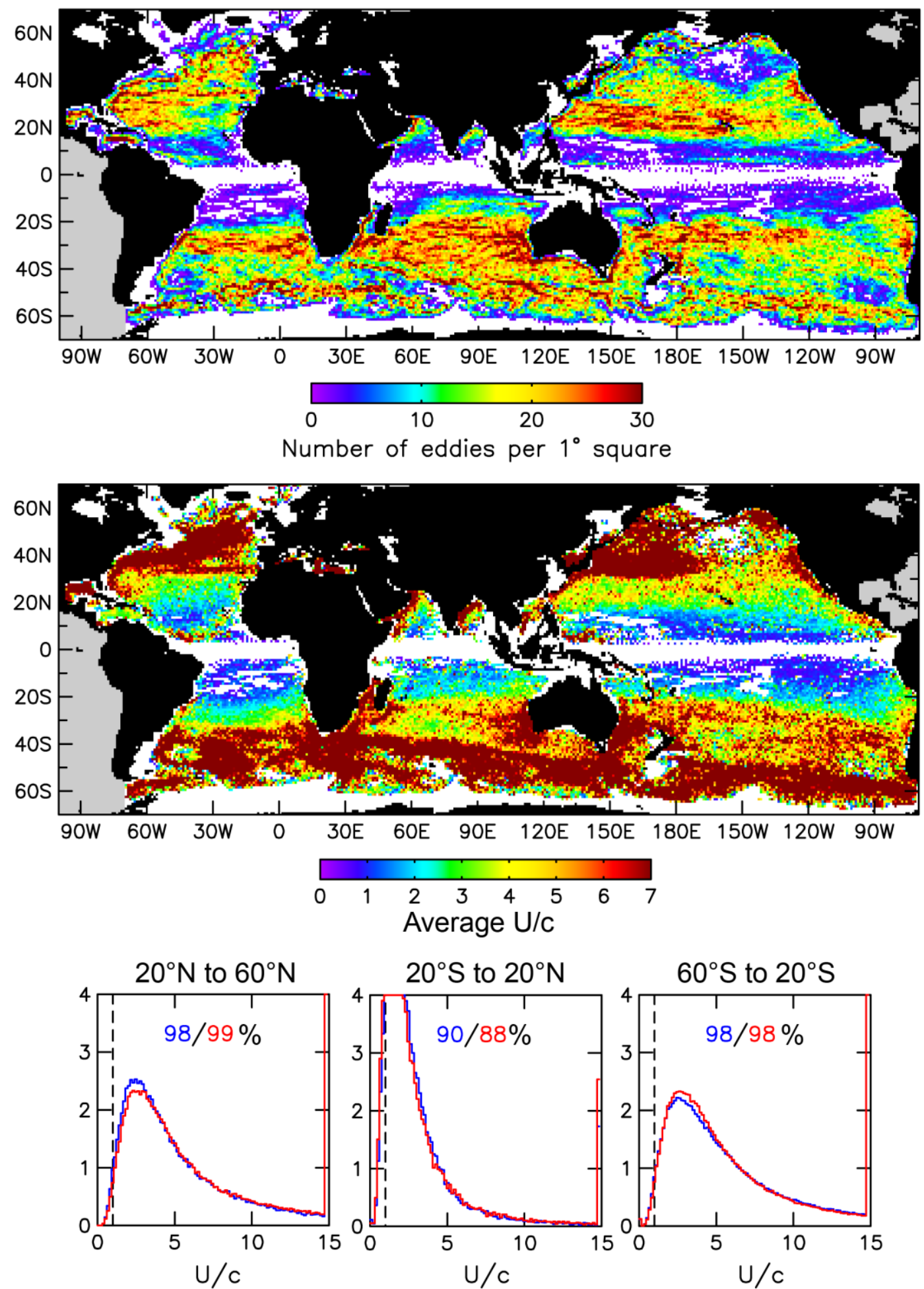

Figure 2: The characteristics of features tracked for 16 weeks and longer over a 15-year data record of merged measurements from two simultaneously operating altimeters [32]. Upper: The number of eddy centres per $1^{\circ}$ square over the 15-year data record. Middle: The average nonlinearity parameter U/c in each $1^{\circ}$ square. Bottom: The distributions (in percent) of the nonlinearity parameter U/C for the observed features in three different latitude bands. (Adapted from [34].) 
The nonlinear character of the westward propagating features has important implications for ocean and climate dynamics. Unlike linear Rossby waves, nonlinear eddies can transport water properties over considerable distances. They also play a vital role in the energetics of ocean currents [36].

\section{ii) Jets and zonal/meridional asymmetry}

On scales $\mathrm{O}(100 \mathrm{~km})$ and $\mathrm{O}(1$ week), a combination of altimetry, drifter trajectories, and winds within a simplified momentum equation [33] and [37] provides an accurate description of mesoscale currents in the near-surface ocean. In this description, drifter data provide the absolute reference to the altimetry dataset, and altimetry corrects biases caused by the highly heterogeneous distribution of drifters. Thus-derived mean dynamic ocean topography [38] revealed complex frontal systems in the Antarctic Circumpolar Current, Gulf Stream, and Kuroshio Extension. In addition, a 'striped' global pattern of new jet-like features ('striations') was unveiled and validated using hydrographic data [39] (Fig. 3, below). While the nature and significance of these striations is not understood yet, the east-west tilt of the striations suggests stationary waves. Striations are also found in the altimetric sea level anomaly [40] which interact with eddies as strongly as the 'mean' striations. Eddies generated and moving along preferred paths may be involved [41] and [42] but this remains controversial [43].

Reference [41] studied the anisotropy of the most energetic length scales, that are partially resolved by the high resolution sea surface height anomaly data from the constellation of at least three simultaneous satellite altimeters monitoring most of the ocean from year 2000 through 2005. They found mesoscale structure in the difference between the eastward and northward velocity variance throughout the extratropical World Ocean, qualitatively consistent with earlier results in the Southern Ocean [44]. The velocity variance structures are within the range of highly nonlinear eddy-eddy interactions. Contrary to the standard nonlinear model of the ocean mesocale as homogenous quasigeostrophic turbulence (e.g. [45]) the structures persist for years, i.e. much longer than the inherent timescales of quasigeostrophic turbulence. The pattern in velocity variance structures suggests an organizing mechanism yet the patterns are not simply related to bathymetry. The most important implications are likely to be the spatially variable and strongly anisotropic dispersion of traces. Climate models may have to resolve the mesoscale explicitly since dispersion parameterization is likely a more formidable challenge than previously appreciated.

\section{iii) Quantifying nonlinear interactions}

In the mesoscale, the flow becomes nonlinear and more complex, and theoretical models only make predictions for statistical flow properties. One of the most fundamental predictions is the so-called inverse energy cascade, in which the large-scale flow gains energy from smaller scales via quasi-2D nonlinear interaction (e.g. [46]). The rate of this inverse cascade, called the spectral kinetic energy flux, was diagnosed as a function of length scale using multisatellite altimeter data, revealing a universal shape over the South Pacific that shifted to larger length scales closer to the Equator [36]. Later analysis confirmed this universal shape throughout the World Ocean, see Fig. 4 below. The spectral flux divergence near the deformation radius suggested baroclinic instability near the deformation radius. This interpretation was later confirmed by comparing the regions of horizontal 2D wavenumber space that are baroclinically unstable, as computed with climatological temperature and salinity data, and with spectral flux measurements computed with altimeter data [47]. These analyses provide the first observational evidence of the importance of beta (resulting from Earth's rotation and curvature) in redirecting the inverse cascade, as anticipated by [25] and clarified by [48] and [49].

While the spectral flux measurements were inspired by classical quasi-2D turbulence theory, their observations required some theoretical developments for consistent interpretation. Classical theory predicts an inverse cascade for the barotropic (depth averaged) flow only, yet analysis of over 100 deep-water, long term, moored current meters spanning the water column suggests that most of the surface flow represents first mode baroclinic motions (vertically sheared flows with strongest signals in the upper ocean) [50]. Thus the inverse cascade seen in altimeter data must imply an inverse cascade of baroclinic KE, a novel idea confirmed with idealized model simulations [51]. 

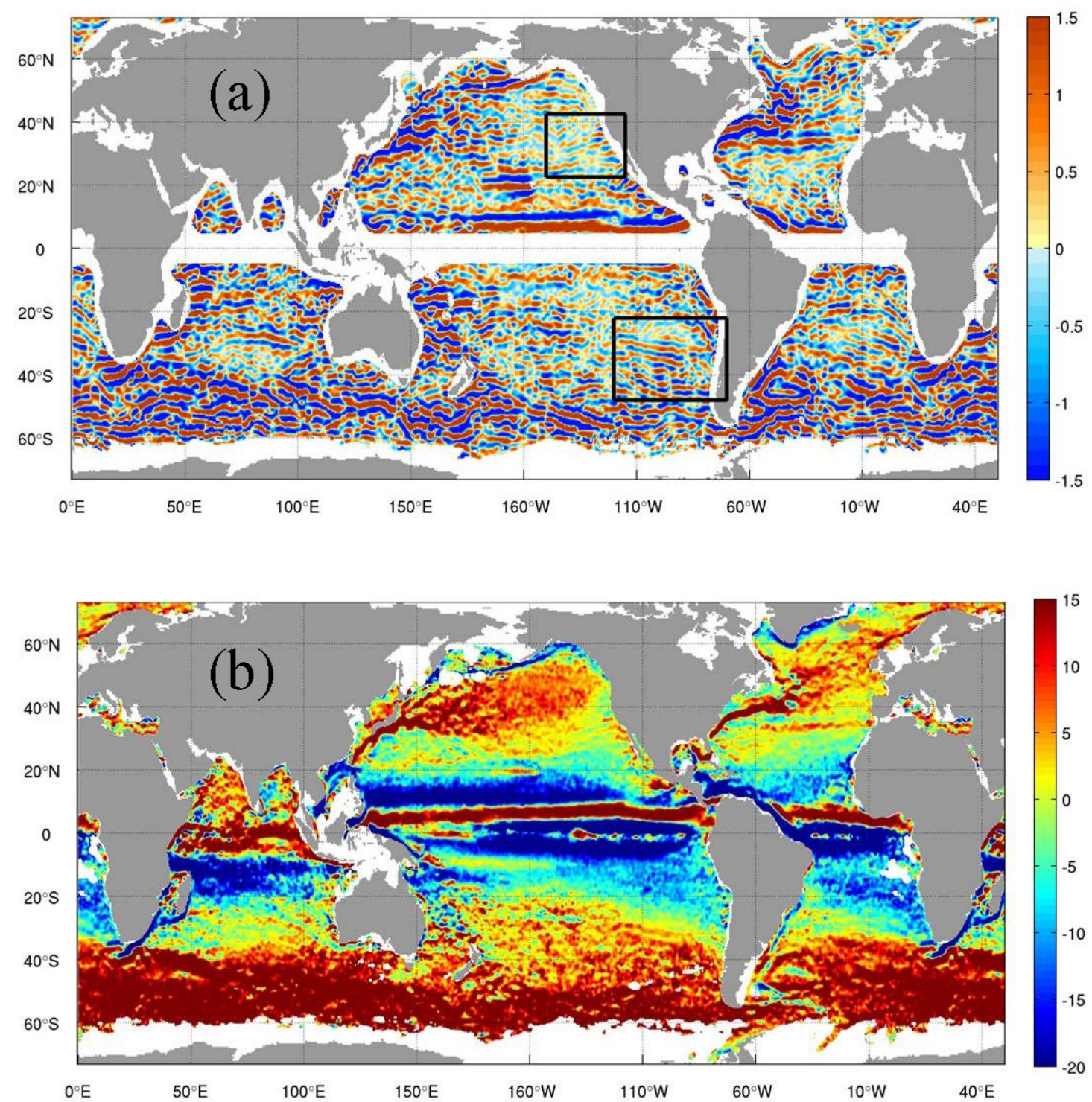

Figure 3: (a) 1993-2002 mean zonal surface geostrophic velocity calculated from the MDOT [37] high-pass filtered with a two-dimensional Hanning filter of $4^{\circ}$ half-width. (b) Ensemble-mean zonal velocity calculated from the data of AOML. Rectangles in (a) outline two study domains where striations are validated by historical XBT data. Units are $\mathrm{cm} / \mathrm{s}$. (Figure from [39].) 

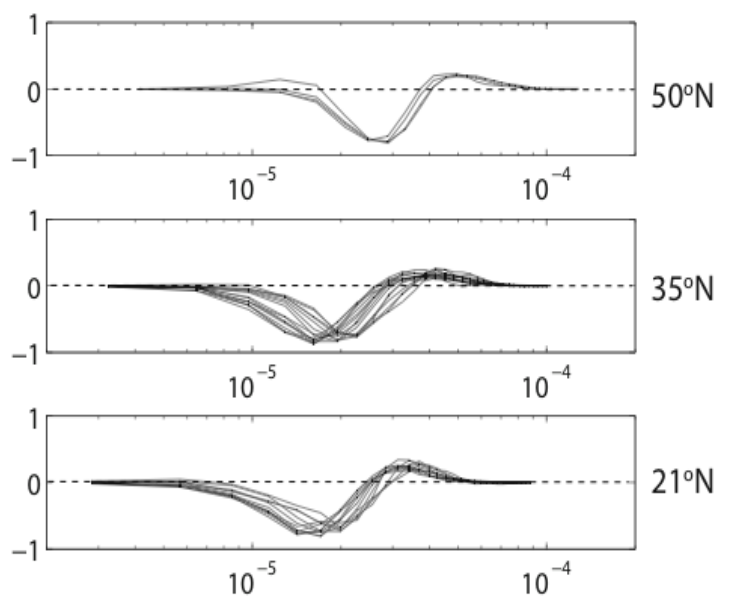

Wavenumber in $\mathrm{rad} / \mathrm{m}$

Figure 4: Spectral kinetic energy flux, normalized by its peak to peak amplitude, vs. wavenumber, calculated from multi-satellite altimeter data on square boxes with width $22^{\circ}$ longitude throughout the Northern Hemisphere. Similar results found in the Southern Hemisphere [36].

\subsection{Quantitative Integration of Multiple Data Types}

i) Need for drifter and float data to complement altimeter data

Altimeter data measure the time-varying geostrophic component of upper ocean velocities but cannot capture the time-mean velocity on mesoscales (since the geoid is only known on large scales) or the windforced ageostrophic velocity associated with Ekman [52] dynamics. Surface drifter data are one way to measure total velocity, and are a valuable complement to altimeter data. Drifters have proved themselves as a useful measure of the time-invariant dynamic ocean topography ([53], [54], [55] and [37], also Sect. 1.2 ii above), allowing detailed assessment of eddy mean flow interactions (e.g. [56] and [57]). Drifters and other in situ data are invaluable for assessing errors in satellite derived surface currents [58].

Argo floats should give us a better estimate of the large-scale vertical stratification than the climatology. Such information is required in the eSQG (effective surface quasi-geostrophy) velocity reconstruction method [59], see Sect. 2.2, discussion around Fig. 6, and altimeter derived estimation of eddy heat fluxes [60].

\section{ii) Critical role of scatterometer vector winds}

Upper ocean currents are wind-forced. Thus, observations of winds play a critical role in the interpretation of the upper ocean currents measured by the altimeter. High-quality scatterometer estimates of wind speed and direction, measured relative to the moving ocean surface, have proved to be the most useful of available satellite wind products. Wind fields provide an estimate of the ageostrophic wind-driven upper ocean velocities that play an important role in advecting water within the upper ocean mixed layer [e.g. [61], [54], [62] and [63]. Also, wind fields define the time-varying forcing of the ocean. As an example, the frontal features that define the Antarctic Circumpolar Current appear to migrate in response to changes in the latitude and character of the wind forcing over a variety of timescales (e.g. 64] and [65]). Detailed analysis of the wind-forced evolution of ocean currents will require coincident high quality altimeter and scatterometer data. Previous estimates of the rate of wind work building the supply of available potential energy in the ocean all used NCEP reanalysis wind stress, which led to significant biases that were revealed and corrected with scatterometer winds [66].

iii) Theoretical advances and observations of upper ocean dynamics

Altimeter data, when analyzed in combination with surface drifter data and coincident wind observations, can provide detailed insights into upper ocean dynamics. Differences between drifter and altimeter motions can be used to identify the transient ageostrophic velocity, revealing the dynamics of windforced motions of the upper ocean (e.g. [61], [54] and [67]). For example, [54] inferred basic physical properties of the upper ocean including vertical viscosity and Ekman layer depth. Reference [68] extended their approach, using the available observations to evaluate what functional form of upper ocean viscosity and what upper ocean boundary conditions would best explain the available observations.

\section{REQUIRED TECHNOLOGICAL ADVANCEMENTS IN SATELLITE ALTIMETRY}

While satellite altimetry has substantially advanced our understanding of the ocean, we know that we are still missing a significant part of ocean variability associated with the submesoscale and smaller spatial scale variability. This variability is believed to have a significant impact on ocean dynamics, especially on small-scale genesis, the interaction of coastal regions or frontal structures with the large-scale circulation, and also the interaction of the physical ocean with biology and biogeochemistry, as explained in more detail below. New technology is available to improve our observing capability of the mesoscale and to expand the sampling capabilities into the submesoscale and coastal domain, with an order of magnitude improvement in resolution.

We anticipate a direct societal benefit from further investment in ocean observing technology will come from supporting the development of ocean forecasting 
and climate prediction. We are now able to produce simulations of the present state of the ocean that compare increasingly well to observations. However, the skill of these models in making long-range predictions of the ocean is still limited, and will likely remain so, partly due to the nonlinearity of the ocean circulation and partly because they lack a physically based representation of the submesoscales, i.e. the more random motions on scales of 1-100 km [69]. Dissipation of momentum is achieved through enhanced vertical viscosities and drag laws with little physical validation. Turbulent transport of tracers like heat, salt, carbon and nutrients is represented with unphysical constant eddy diffusivities. Ocean models running at sufficient resolution to address submesoscale dynamics have just begun to emerge [70], but we need global observations at these scales to guide model development.

\subsection{New Technologies: Delay-Doppler Altimetry and Wide-swath Altimetry}

Nadir-pointing along-track altimetry is about to undergo a dramatic improvement, which will be made possible by the adoption of delay-Doppler processing of the echo returns. Delay-Doppler altimetry (DDA) was proposed in the 1990s [71] as a more efficient alternative to conventional altimetry. DDA uses the Doppler information contained in the returns (and essentially due to the satellite motion with respect to the surface) to resolve iso-Doppler subregions within the area illuminated by each altimetric pulse; therefore it allows an integration of the contributions coming from a large number of multiple looks on the same along-track Doppler cell. The result is either a much higher along-track resolution (the along-track cell is of the order of a few hundred meters; across track it is limited by the antenna beamwidth so of $\mathrm{O}(10 \mathrm{~km}))$, or an improved signal to noise ratio (possible by averaging several independent along-track cells), or any intermediate trade off between enhanced resolution and enhanced SNR. Another beneficial characteristic is a reduced sensitivity of the measurements on the sea state. The first DDA in space will be the CryoSat-2 altimeter due to be launched in late 2009, and ESA (The European Space Agency) is going to adopt the DD paradigm also for the Sentinel-3 altimeter, successor to the ERS and Envisat instruments. The combination of improved resolution and precision of this new family of instruments holds great promise for observations of the submesoscale; moreover, they are expected to give a significant contribution to the emerging field of coastal altimetry [see 72].

Surface Water Ocean Topography (SWOT) mission utilizes the new technology of a swath of width $\sim 130$ $\mathrm{km}$ [73], with both ocean dynamics and land hydrological applications. This mission, if funded, will dramatically improve the resolution of SSH fields, allowing investigation of submesoscale variability with scales approximately an order of magnitude smaller than can presently be resolved from the merging of observations from conventional altimeters. The same mission will also provide revolutionary measurements of river and lake levels. The data-downlink requirements (for both ocean and inland waters) can be met with eight 300-Mbps X-band stations globally (http://decadal.gsfc.nasa.gov/documents/SWOT_Techn ology_Investments.pdf). The SWOT mission was recommended recently by the National Research Council's Decadal Survey. Preliminary estimates of the performance of the SWOT measurement system indicate that measurement noise below $3 \mathrm{~cm}$ at $1 / \mathrm{km}$ sampling rate is within the range of the present technology. The noise spectra for $3 \mathrm{~cm}$ and $1 \mathrm{~cm}$ noise levels at $1 / \mathrm{km}$ sampling rate are plotted in Figure 5. If we extrapolate the SSH spectrum along the same power law from wavelengths longer than $100 \mathrm{~km}$ down to wavelengths of $1 \mathrm{~km}$, we then find the intersection of the signal spectrum with the noise spectra at $30 \mathrm{~km}$ and $10 \mathrm{~km}$ wavelengths for $3 \mathrm{~cm}$ and $1 \mathrm{~cm}$ noise level, respectively. In order to resolve the narrow currents and fronts in the ocean, we must resolve signals at wavelengths down to $10 \mathrm{~km}$, pushing the measurement requirement to a noise level of $1 \mathrm{~cm}$ at $1 / \mathrm{km}$ sampling rate, compared to the noise of $5 \mathrm{~cm}$ at $1 / \mathrm{km}$ sampling rate for the Jason altimeter. 


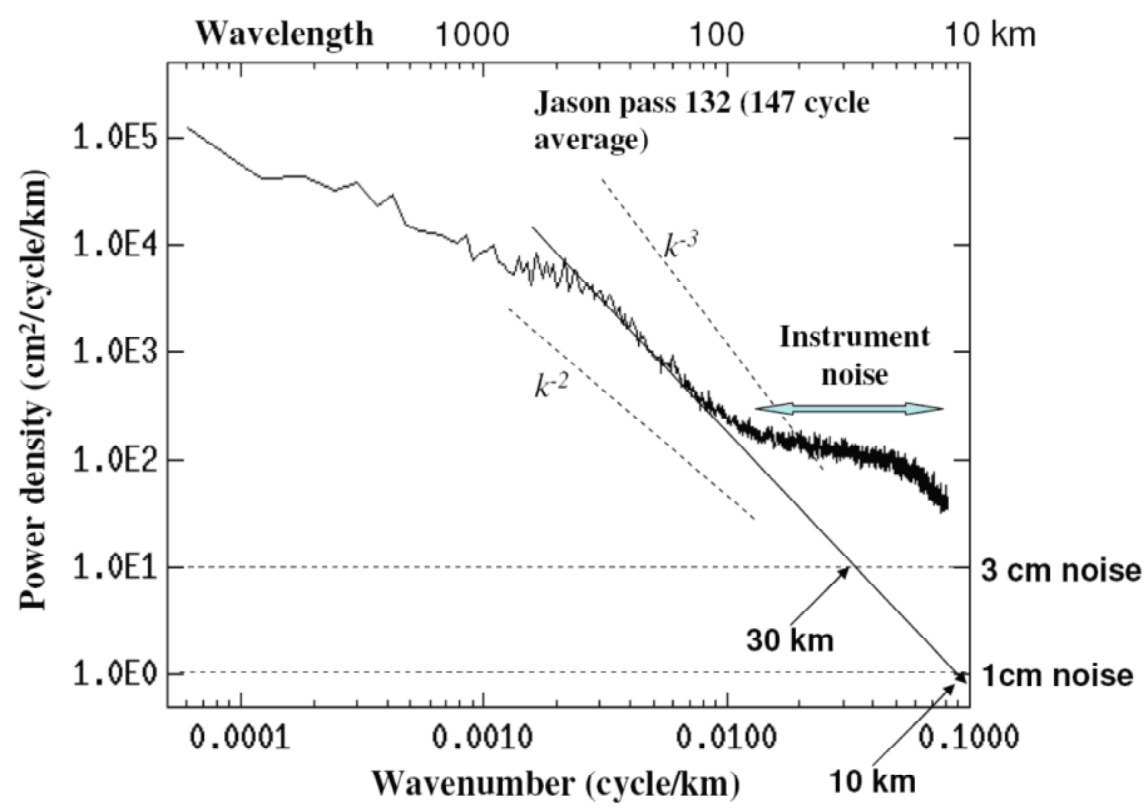

Figure 5: Wavenumber spectrum of sea surface height anomaly from 147 repeat measurements along Jason pass 132 (solid line). The two slanted dashed lines represent two spectral power laws with $k$ denote wavenumber. The two horizontal dashed lines represent two levels of measurement noise at 1/km sampling rate: $3 \mathrm{~cm}$ and $1 \mathrm{~cm}$. The slanting solid straight line represents a linear fit of the spectrum in the range between 0.002 and $0.01 \mathrm{cycles} / \mathrm{km}$. It intersects with the two noise level lines at $30 \mathrm{~km}$ and $10 \mathrm{~km}$ wavelengths.

This performance in SSH measurement translates to a geostrophic velocity error of $3 \mathrm{~cm} / \mathrm{sec}$ at $10 \mathrm{~km}$ wavelength at $45^{\circ}$ latitude. The two dimensional SSH map from SWOT will observe these features and will thereby allow the study of the submesoscale ocean eddies, fronts, narrow currents, and even the vertical velocity at these scales. However, to capture related temporal variability one would still need more than one SWOT mission.

Despite the promise of the SWOT mission, we speculate $^{* *}$ that grappling with the following issues could maximize the benefit of the mission:

- Error statistics confronting effective use of SAR altimetry will change across the swath due to the change in resolving capability of an interferometer. Are error statistics also isotropic in such data?

- How relevant are assumptions about constant e-m bias etc. with coherent altimeter systems?

- Data assimilation of $2 \mathrm{~d}$ interferometrically-derived heights will have to be accompanied by some kind

\footnotetext{
** We thank an anonymous reviewer for suggesting
} these areas. of $2 \mathrm{~d}$ height error covariance functions in order to assimilate the data, which is not a trivial issue.

\subsection{Potential breakthroughs in ocean dynamics and biogeochemistry}

Global observations of the oceanic submesoscale are essential to quantifying the ocean uptake of climate relevant tracers such as heat and carbon. Traditional altimeters revealed the fundamental role of mesoscale eddies in the horizontal transport of tracers. Recent theoretical work suggests that submesoscale motions play a leading role in the vertical transport [74], [75], [70] and [76]. Vertical velocities in the ocean require higher spatial resolution because they result from convergences and divergences in the horizontal velocity field. Submesoscale motions at the ocean surface are a superposition of Ekman velocities driven by the wind, geostrophic velocities modified by finite Rossby number dynamics. Scatterometers provide detailed measurements of the wind stress field and allow estimates of the wind-driven vertical velocities. First attempts [77] and [78] to reconstruct the 3D circulation in the upper $300 \mathrm{~m}$ from climatological data and high-resolution SST are quite promising. However the high resolution $\mathrm{SSH}$ of wide-swath interferometry is necessary to bring the approach to full fruition and provide global maps of the vertical velocities 
associated with geostrophic motions. Our understanding of the ocean and its role in climate would be radically advanced should such maps become available. One first step in that direction will be the availability of high-resolution (1-D) delay-Doppler altimetry together with 2-D SST and ocean colour fields made possible by Sentinel-3.

Attempts to further diagnose the oceanic circulation in a realistic situation involving a mesoscale eddy field with large Rossby numbers and an active mixed-layer forced by high frequency winds have been recently achieved [59]. Results (see Fig. 6) reveal that, despite the presence of energetic near-inertial motions, a snapshot of high resolution SSH allows reconstruction of low frequency motions, including the vertical velocities, for scales between $400 \mathrm{~km}$ and $20 \mathrm{~km}$ and depths between the mixed-layer base and $500 \mathrm{~m}$. As such these results highlight the potential of highresolution $\mathrm{SSH}$ to assess in the upper ocean the low frequency horizontal and vertical fluxes of momentum and tracers driven by mesoscale and submesoscale dynamics. Some work still to be done to improve this simple diagnosis method including its testing in a broader range of mesoscale eddy and mixed-layer regimes and its improvement to diagnose the specific mixed-layer dynamics. a

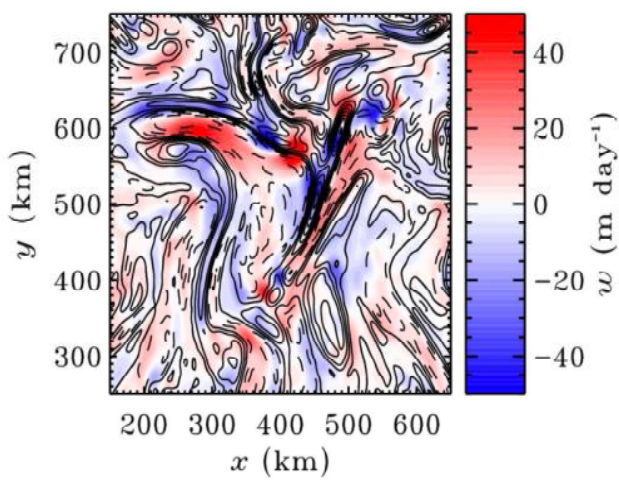

b

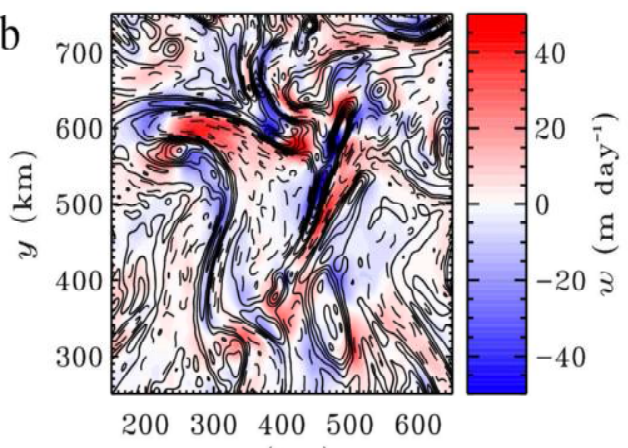

$$
x(\mathrm{~km})
$$
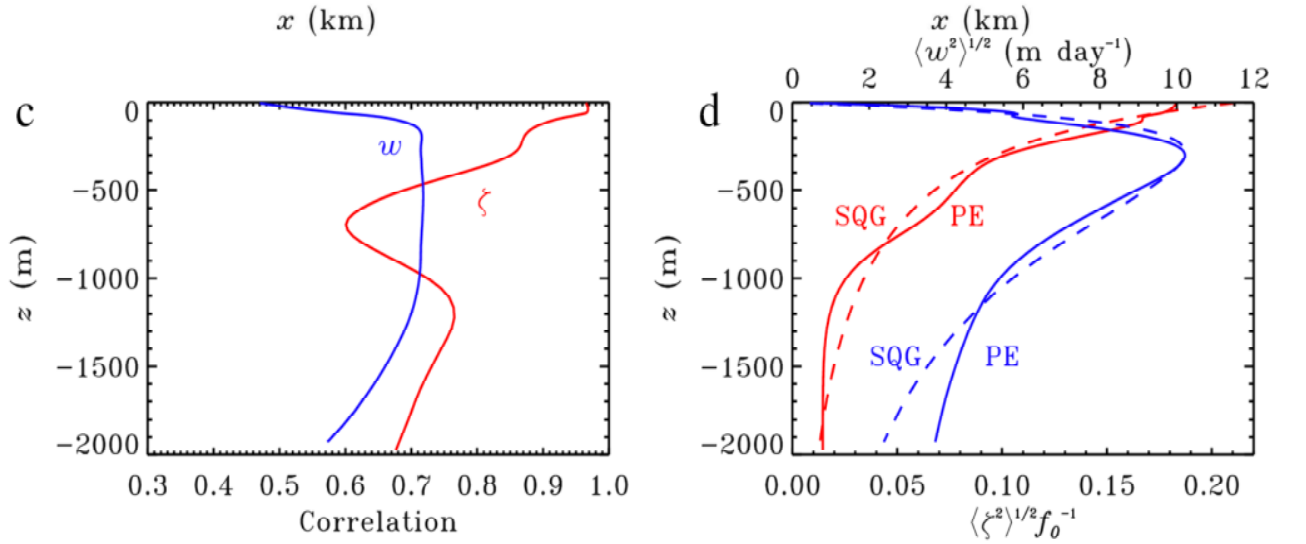

Figure 6: a) Observed low-frequency vertical velocity (in colors) and relative vorticity (contours) at $200 \mathrm{~m} . b$ ) eSQG reconstructed vertical velocities(in colors) and relative vorticity (contours) at $200 \mathrm{~m}$. c) Correlation between observed and eSQG reconstructed vertical velocities (blue line) and relative vorticity (red line). d) Vertical velocities RMS (Root-

Mean-Square) (blue) and relative vorticity RMS (red) observed in the PE simulation (solid line) and reconstructed using eSQG (dashed line). Figure from [59].

The uptake of heat and carbon by the ocean is complete only after these properties are transported away from the surface turbulent boundary layer into the ocean interior. Vertical velocities associated with divergences and convergences of geostrophically balanced velocities on $10 \mathrm{~km}$ scale penetrate down to a few hundred meters below the ocean surface [74]. Hence, the resolution of delay-Doppler altimeters and SWOT will allow one to compute the exchange of properties between the ocean surface boundary layers and the interior. Furthermore, these measurements will be fundamental to improving the skills of coupled climate models that are very sensitive to the exchange of properties between the ocean and the atmosphere.

Other applications of the 1-D and 2-D SSH measurements at the submesoscale are for estimates of biological productivity. Ocean colour is very often characterized by a web of filaments of enhanced biological activity. It is impossible from a surface picture to determine whether these filaments are associated with lateral stirring of biomass or with new 
productivity resulting from vertical advection of new nutrients into the filaments. The distinction is crucial for the global carbon cycle; the latter case implies an enhancement of the biological carbon pump. Therefore, delay-Doppler and wide-swath missions could contribute essential new information to further our understanding of the submesoscale physics and biology of the upper ocean.

\section{INTEGRATING EMERGING TECHNOLOGIES WHILE MAINTAINING EXISTING TECHNOLOGIES}

Most climate records have been obtained as the byproduct of measurements made for a different purpose, especially weather observations, and commonly it is asserted that simply sustaining these networks is the surest way to determining changes in climate. This approach often generates some very great and intractable difficulties. By some arguments, the sustenance of high quality, sometimes demanding, but nonetheless routine, measurements are the most difficult of all to obtain and for many reasons. Each oceanographic data type is in need of constant supervision by technically qualified scientists who can determine if standards are being followed, that calibration protocols have been adhered to, and is in a position to influence a decision to change a data type. Because the intellectual payoff of many records might be decades in the future, incentives have to be provided for scientists to invest their time and energies into efforts with little personal gratification other than a sense of doing a service to the community.

Many examples of difficult decisions about technology change abound. Therefore, given those experiences, we should continue TOPEX-Jason class altimeters even though the next generation of altimeters will have swath capabilities. (Note that there remain calibration discrepancies between radar altimeters.) Only if we can assume the indefinite existence of high-quality altimeters, the tide gauge network could be thinned. On the other hand, in situ data are essential for calibrating data from individual altimeter missions. In addition, sea level has proven to vary on small coastal scale and to monitor sea level changes we might even need to expand the existing tide gauge network. Argo floats should be redesigned to reach the sea floor. Investigations should be carried out to determine whether the surface observing system could be reduced, but at this point no indication exists that the ocean is oversampled - just the opposite. In the same vein, we need to investigate whether scatterometers should completely replace the surface anemometer network apart from a few very high quality calibration positions. These questions will need to be answered before we can decide what kind of investment should be made in meteorological buoys. These are difficult problems that cannot be relegated to uninterested committees for solution. To answer them requires a serious and quantitative design study of the observing system, which addresses also uncertainties in the observations, the models and the estimates that we obtain by bringing observations and models together. An ocean observing system that is intended to truly address climate change must have a scientific supporting infrastructure that is in constant control of the system.

\section{INTEGRATING AND OPTIMIZING THE GLOBAL OBSERVING SYSTEM: THE GREAT CHALLENGE FOR COMING DECADES}

Ocean data assimilation provides an objective way of combining observational data on multiple variables in a dynamically consistent framework, and forms the backbone of ocean state estimation and ocean weather forecasting. The most direct societal benefits from ocean observations will come from the forecasting of the ocean state, which impacts ship routing, weather forecasting, the marine resources industry, etc. A great challenge for the coming decade is the coordination of ocean observations to optimize ocean state estimation and forecasting through data assimilation. The altimeter community in particular will need to coordinate with the ocean modeling community to devise experiments to determine what combination of satellites in which orbits, carrying what combination of sensors (conventional, delayed Doppler, swath) will have the greatest impact on ocean state estimation and forecasting. These are complex questions. Experience from preliminary studies underway suggests that ultimate decisions may involve subjective choices of goals (e.g. large scale or mesoscale? surface or barotropic? currents or transports?) and metrics to decide which forecast is best.

While the needs of data assimilation provide a unique method to guide resource development, we emphasize that better forecasts are not the only consideration. The dynamics of the ocean and its interaction with marine biology and Earth's climate remain basic research areas, and the immediate benefits are less clear, but the longterm rewards may be most revolutionary. Basic research may call for resources distinct from operational oceanography. For example the highly nonlinear submesoscale SSH field from SWOT might not benefit data assimilation in present generation OGCMs (Ocean General Circulation Models), but might provide crucial information for understanding mixed layer biological interactions.

The optimized system will likely include the constellation of satellites that optimize operational oceanography for some compromise set of criteria, and some exploratory missions that push the frontiers of basic science. We anticipate that SWOT and delayed Doppler altimeters will form key components of a 
constellation of altimeters.

\section{REFERENCES}

1. Fu, L.-L., and A. Cazenave, editors, (2001): Satellite Altimetry and Earth Sciences: A Handbook of Techniques and Applications, Academic Press, San Diego, 463 pp.

2. Stammer, (1997): Global characteristics of ocean variability estimated from regional TOPEX/POSEIDON altimeter measurements, J. Phys. Oceanogr., 27, 17431769.

3. Smith, R.D., Maltrud, M.E., Bryan, F.O., and Hecht, M.W., (2000): Numerical simulation of the North Atlantic ocean at $1 / 10^{\circ}$. J. Phys. Oceanogr., 30, 7 , $1532-1561$

4. Chelton DB and Schlax MG, (1996): Global observations of oceanic Rossby waves, Science, Volume: 272 Issue: 5259, Pages: 234-238.

5. Fu LL and Chelton DB (2001): Large-scale Ocean circulation. In "Satellite altimetry and Earth Sciences", $\mathrm{Fu}$ and Cazenave editors, International Geophysics Series. Volume 69. Pages: 133-165

6. Killworth PD, Chelton DB, de Szoeke RA, (1997): The speed of observed and theoretical long extratropical planetary waves. J. Phys. Oceanogr. Volume: 27, Issue: 9, Pages: 1946-1966.

7. Tailleux R and McWilliams, JC, (2001): The effect of bottom pressure decoupling on the speed of extratropical, baroclinic Rossby waves. J. Phys. Oceanogr. Volume: 31, Issue: 6, Pages: 1461-1476

8. Killworth PD and Blundell JR, (2003a): Long extratropical planetary wave propagation in the presence of slowly varying mean flow and bottom topography. Part I: The local problem. J. Phys. Oceanogr. Volume: 33, Issue: 4, Pages: 784-801.

9. Killworth PD and Blundell JR, (2003b): Long extratropical planetary wave propagation in the presence of slowly varying mean flow and bottom topography. Part II: Ray propagation and comparison with observations. J. Phys. Oceanogr. Volume: 33, Issue: 4, Pages: 802-821.

10. Killworth PD and Blundell JR, (2004): The dispersion relation for planetary waves in the presence of mean flow and topography. Part I: Analytical theory and onedimensional examples. J. Phys. Oceanogr. Volume: 34 Issue: 12, Pages: 2692-2711.

11. Killworth PD and Blundell JR, (2005): The dispersion relation for planetary waves in the presence of mean flow and topography. Part II: Two-dimensional examples and global results. J. Phys. Oceanogr. Volume: 35, Issue: 11, Pages: 2110-2133.
12. Tailleux R and Maharaj AM, (2009): On the zonal wavenumber/frequency spectrum of westward propagation. Part I: Theory. To be submitted.

13. Wunsch, C. (2009): The Oceanic Variability Spectrum and Transport Trends, Atmosphere-Ocean, 47(4), 281-291, doi:10.3137/OC310.2009.

14. Maharaj AM, Holbrook NJ, and Cipollini, P (2009): An assessment of multiple westward propagating signals in sea level anomalies. Submitted to J. Geophys. Res. Oceans, 114, (C12016) pp. 1-14. doi:10.1029/2008JC004799

15. Mantua, N. J., S. R. Hare, Y. Zhang, J. M. Wallace and R. C. Francis (1997): A Pacific interdecadal climate oscillation with impacts on salmon production. Bull. Amer. Meteor. Soc., 78, 1069-1079.

16. Miller, A. J., D. R. Cayan, and W. B. White, (1998): A westward intensified decadal change in the North Pacific thermocline and gyre-scale circulation. J. Clim., 11, 3112-3127.

17. Deser, Clara, Michael A. Alexander And Michael S. Timlin, (1999): Evidence for a Wind-Driven Intensification of the Kuroshio Current Extension from the 1970s to the 1980s , J. Clim., Vol. 12, pp. 1697 1706.

18. Seager, R., Y. Kushnir, N. H. Naik, M. A. Cane, and J. Miller, (2001): Wind-driven shifts in the latitude of the Kuroshio-Oyashio extension and generation of SST anomalies on decadal timescales. J. Clim., 14, 42494265 .

19. Schneider, N., A. J. Miller, and D. W. Pierce, (2002): Anatomy of North Pacific decadal variability. J. Clim., 586-605.

20. Qiu, B. and S. Chen (2005b): Variability of the Kuroshio Extension Jet, Recirculation Gyre, and Mesoscale Eddies on Decadal Time Scales, J. Phys. Oceanogr., Vol. 35, pp. 2090-2103.

21. Taguchi et al. Decadal Variability of the Kuroshio Extension, (2007): Observations and an Eddy-Resolving Model Hindcast, J. Clim. Vol. 20, pp. 2357-2377.

22. Kistler, R. E., Kalnay, E. M. W. Collins, S. Saha, G. White, J. Woollen, M. Chelliah, W. Ebisuzaki, M. Canamitsu, V. Kousky, H. van den Dool, R. Jenne and M. Fiorinio, (2001): The NCEP/NCAR 50-year reanalysis: Monthly means CD-ROM and documentation, Bull. Amer. Met. Soc, Vol. 82, pp. 247267.

23. Lorenz, E. (1963): Deterministic nonperiodic flow, $J$. Atmos. Sci., Vol. 20, pp. 130-141.

24. Charney, J.G. (1971): Geostrophic Turbulence, J. Atmos. Sci. Vol. 28, pp. 1087-1095. 
25. Rhines, P. (1975): Waves and turbulence on a beta-plane, J. Fluid Mech., Vol. 69, pp. 417—443.

26. McWilliams, J. C., and G. R. Flierl (1979): On the evolution of isolated, nonlinear vortices, J. Phys. Oceanogr., 9, 1155-1182.

27. Salmon, R. (1980): Baroclinic Instability And Geostrophic Turbulence, Geophys. Astrophys. Fluid Dyn., Vol. 15, pp. 167-211.

28. Hua, B.L. and Haidvogel, D. (1986): Numerical simulations of the vertical structure of quasi-geostrophic turbulence, J. Atmos. Sci., Vol. 43, pp. 2923-2936.

29. Treguier, A. and L. Panetta, (1994): Multiple Zonal Jets in a Quasigeostrophic Model of the Antarctic Circumpolar Current, J. Phys. Oceanogr., Vol. 24, pp. 2263-2277.

30. Jiang, S., F. Jin and M. Ghil, (1995): Multiple equilibria, Periodic and Aperiodic solutions in a wind-driven, double-gyre, shallow-water model, J. Phys. Oceanogr., Vol. 25, pp. 764-786.

31. Chelton, D.B. and Schlax, M.G. (2003): The accuracies of smoothed sea surface height fields constructed from tandem satellite altimeter datasets, J. Atmos. Oceanic Technol., Vol. 20, pp. 1276-1302.

32. Ducet, N., P.-Y. Le Traon, and G. Reverdin, (2000): Global high resolution mapping of ocean circulation from TOPEX/POSEIDON and ERS-1/2. J. Geophys. Res., 105, 19,477-19,498.

33. Pascual, A., Faugere, Y., G. Larnicol, P.Y. Le Traon, (2006): Improved description of the ocean mesoscale variability by combining four satellite altimeters. Geophys. Res. Letters, 33 (2): Art. No. L02611.

34. Chelton, D. B., M. G. Schlax, R. M. Samelson, and R. A. de Szoeke, (2007): Global observations of large oceanic eddies. Geophys. Res. Lett., 34, L15606, doi:10.1029/2007GL030812.

35. Tulloch, R. and J. Marshall and K. S. Smith: (2009): Interpretation of the propagation of surface altimetric observations in terms of planetary waves and geostrophic turbulence, J. Geophys. Res. Oceans, Vol. 114, doi:10.1029/2008JC005055.

36. Scott, R.B. and F. Wang (2005): Direct evidence of an oceanic inverse kinetic energy cascade from satellite altimetry, J. Phys. Oceanogr, Vol. 35, pp. 1650-166.

37. Maximenko, N.A., and P.P. Niiler, (2005): Hybrid decademean global sea level with mesoscale resolution. In N. Saxena (Ed.) Recent Advances in Marine Science and Technology, (2004), pp. 55-59. Honolulu: PACON International.
38. Maximenko, N., P. Niiler, M.-H. Rio, O. Melnichenko, L. Centurioni, D. Chambers, V. Zlotnicki, and B. Galperin, (2009): Mean dynamic topography of the ocean derived from satellite and drifting buoy data using three different techniques. (2009): J. Atmos. Oceanic Technol., Vol. 26, pp. 1910--1919.

39. Maximenko, N.A., O. V. Melnichenko, P. P. Niiler, and H. Sasaki, (2008): Stationary mesoscale jet-like features in the ocean. (2008): Geophys. Res. Lett., 35, L08603, doi:10.1029/2008GL033267.

40. Maximenko, N.A., B. Bang, and H. Sasaki, (2005): Observational evidence of alternating zonal jets in the World Ocean. Geophys. Res. Lett., 32, L12607, doi:10.1029/2005GL022728.

41. Scott, R.B., Arbic, B.K., Holland, C.L., Sen, A., and Qiu, B. (2008): Zonal versus meridional velocity variance in satellite observations and realistic and idealized ocean circulation models, Ocean Modelling, Vol. 23, pp $102-112$.

42. Schlax, Michael G. and Dudley B. Chelton, (2008): The influence of mesoscale eddies on the detection of quasizonal jets in the ocean, Geophys. Res. Lett., VOL. 35, L24602, doi:10.1029/2008GL035998.

43. Maximenko, N. A., O. V. Melnichenko, and H.-P. Huang, (2009): Are oceanic striations an artefact of moving eddies? In prep.

44. Morrow, R.A., R. Coleman, J.A Church, and D.B. Chelton, (1994): Surface eddy momentum flux and velocity variances in the Southern Ocean from Geosat altimetry. J. Phys. Oceanogr., 24, 2050-2071.

45. Arbic, B.K. and Flierl, G.R. (2004): Effects of mean flow direction on energy, isotropy, and coherence of baroclinically unstable beta-plane geostrophic turbulence, J. Phys. Oceanogr., Vol. 34, pp. 77-93.

46. Charney, J.G. (1971): Geostrophic Turbulence, J. Atmos. Sci. Vol. 28, pp. 1087-1095.

47. Qiu, B., R.B. Scott, and S. Chen, (2008): Length-scales of generation and nonlinear evolution of the seaonallymodulated South Pacific Subtropic Countercurrent, $J$. Phys. Oceanogr., Vol. 38, pp. 1515-1528.

48. Vallis, G.K. and M. Maltrud, (1993): Generation of mean flows and jets on a beta plane and over topography, $J$. Phys. Oceanogr., Vol. 23, pp. 1346-1362.

49. Sukoriansky, S., N. Dikovskaya, and B. Galperin, (2007): On the 'arrest' of the inverse energy cascade and the Rhines scale, J. Atmos. Sci., 64, 3312-3327. 
50. Wunsch, C. (1997): The vertical partition of oceanic horizontal kinetic energy and the spectrum of global variability, J. Phys. Oceanogr., Vol.27, pp. 1770-1794.

51. Scott, R.B. and B.K. Arbic (2007): Spectral energy fluxes in geostrophic turbulence: implications for ocean energetic, J. Phys. Oceanogr, Vol. 37, pp. 673-688.

52. Ekman, V.W. (1905): On the influence of the earth's rotation on ocean currents. Ark. Mat. Astron. Fys. 2 (11): $1-52$.

53. Niiler, P. P. and N. A. Maximenko and J. C. McWilliams, (2003): Dynamically balanced absolute sea level of the global ocean derived from near-surface velocity observations, Geophys. Res. Lett., 30:22, 2164, doi:10.1029/2003GL018628.

54. Rio, M.-H. and F. Hernandez, (2003): High frequency response of wind-driven currents measured by drifting buoys and altimetry over the world ocean, J. Geophys. Res., 108(C8), 3283, doi:10.1029/2002JC001655.

55. Rio, M. H. and F. Hernandez, (2004): A mean dynamic topography computed over the world ocean from altimetry, in situ measurements, and a geoid model, $J$. Geophys. Res., 109, C12032, doi:10.1029/2003JC002226.

56. Hughes, C. W. and Ash E. R., (2001): Eddy forcing of the mean flow in the Southern Ocean, J. Phys. Oceanogr., 31(10), pp.2871-2885.

57. Hughes, C. W., (2005): Nonlinear vorticity balance of the Antarctic Circumpolar Current, J. Geophys. Res., 110, C11008, doi:10.1029/2004JC002753.

58. Johnson, E.S., F. Bonjean, G.S.E. Lagerloef, J.T. Gunn, and G. T. Mitchum, (2007): Validation and Error Analysis of OSCAR Sea-surface Currents, J. of Atmos. Oceanic Technol., 24(4), 688-701.

59. Klein P., J. Isern-Fontanet, G. Lapeyre, G. Roullet, E. Danioux, B. Chapron, S. LeGentil and H. Sasaki, (2009): Diagnosis of vertical velocities in the upper ocean from high resolution Sea Surface Height. Geophys. Res. Lett., 36, L12603, doi:10.1029/2009GL038359.

60. Qiu, B. and S. Chen (2005a): Eddy-Induced Heat Transport in the Subtropical North Pacific from Argo, TMI, and Altimetry Measurements, J. Phys. Oceanogr. Vol. 35, pp. 458-473.

61. Ralph, E. A. and P. P. Niiler, (1999): Wind-driven currents in the tropical Pacific, J. Phys. Oceanogr., 29, pp. 2121--2129.

62. Dong, S., S. T. Gille, J. Sprintall, (2007): An assessment of the Southern Ocean mixed-layer heat budget, J. Clim., $20,4425-4442$.
63. Bonjean, F., and G.S.E. Lagerloef, (2002): Diagnostic model and analysis of the surface currents in the tropical Pacific Ocean, J. Phys. Oceanogr., 32, 2938-2954.

64. Dong, S., J. Sprintall, and S. T. Gille, (2006): Location of the Polar Front from AMSR-E satellite sea surface temperature measurements, J. Phys. Oceanogr., 36, 2075-2089.

65. Sallée, J.-B., K. Speer, and R. Morrow, (2008): Southern Ocean fronts and their variability to climate modes, $J$. Clim., 21(12), 3020-3039.

66. Scott, R.B. and Xu, Y. (2009): An update on the wind power input to the surface geostrophic flow of the World Ocean, Deep Sea Research I, Vol. 56, pp. 295-304.

67. Elipot, S. and S. T. Gille, (2009a): Estimates of wind energy input to the Ekman layer in the Southern Ocean from surface drifter data, J. Geophys. Res., Vol. 114, doi:10.1029/2008JC005170.

68. Elipot, S. and S. T. Gille, S. T., (2009b): Ekman layers in the Southern Ocean: spectral models and observations, vertical viscosity and boundary layer depth, submitted Ocean Sci. Discuss., 6, 277-341.

69. Nature, editorial (2008): "The next big climate challenge". Nature, Vol. 453, Issue no. 7193, p. 257.

70. Capet, X., J.C. McWilliams, M.J. Molemaker, and A.F. Shchepetkin, (2008): Mesoscale to submesoscale transition in the California Current System. Part I: Flow structure, eddy flux, and observational tests. J. Phys. Oceanogr., Vol. 38, 29-43.

71. Raney, R. K., (1998): The delay Doppler radar altimeter, IEEE Transactions on Geoscience and Remote Sensing, vol. 36 , pp. 1578-1588.

72. Cipollini, P. \& Co-Authors (2010). "The Role of Altimetry in Coastal Observing Systems" in these proceedings (Vol. 2), doi:10.5270/OceanObs09.cwp.16.

73. Fu, L.-L., and R. Rodriguez, (2004): High-resolution measurement of ocean surface topography by radar interferometry for oceanographic and geophysical applications, AGU Geophysical Monograph 150, IUGG Vol. 19: "State of the Planet: Frontiers and Challenges", R.S.J. Sparks and C.J. Hawkesworth, editors, 209-224.

74. Lapeyre, G., P. Klein, and B. L. Hua, (2006): Oceanic restratification forced by surface frontogenesis. J. Phys. Oceanogr., 36, 1577-1590.

75. Boccaletti G., R. Ferrari, and B. Fox-Kemper, (2007): Mixed Layer Instabilities and Restratification, J. Phys. Oceanogr., 37, 2228-2250.

76. Klein, P., Hua B.L., G. Lapeyre, X. Capet, S. LeGentil and H. Sasaki., (2008): Upper Ocean Dynamics from High 3-D Resolution Simulations. J. Phys. Oceanogr., 38, pp. 1748-1763. 
77. Lapeyre, G., and P. Klein, (2006): Dynamics of upper oceanic layers in terms of surface quasigeostrophic theory. J. Phys. Oceanogr., 36, 165-176.

78. LaCasce, J. H. and A. Mahedavan, (2006): Estimating sub-surface horizontal and vertical velocity from sea surface temperature. J. Mar. Res., 64, 695-721. 